\title{
ANOMALOUS ORIGIN OF THE LETT MAIN CORONARY ARTERY FROM THE RIGHT AORTIC SINUS WITH INTRAMYOCARDIAL TUNNELING THROUGH THE SEPTUM WITH FREE PORTION IN THE RIGHT VENTRICULAR CAVITY
}

Jaime F. Vazquez-Jimenez, MD, ${ }^{a}$ Philipp K. Haager, MD, ${ }^{\mathrm{b}}$ Mechthild Genius, MD, ${ }^{\mathrm{b}}$ Markus Eblenkamp, MD,

Heinrich G. Klues, MD, ${ }^{\mathrm{b}}$ Peter Hanrath, MD, ${ }^{\mathrm{b}}$ and Bruno J. Messmer, MD, ${ }^{\mathrm{a}}$ Aachen, Germany

Anomalous origin of the left main coronary artery from the right aortic sinus or from the right coronary artery with intramyocardial tunneling to the left side of the heart through the ventricular septum is a widely known malformation. Much controversy exists concerning the clinical relevance of this condition since older anatomic studies showed a much higher incidence at autopsy than clinical series. ${ }^{1}$ On the other hand, this condition is sometimes the sole cardiac anomaly in patients with sudden and unexpected death, ${ }^{2}$ the mechanism remaining unknown. We report a new anatomic variation with a free portion of the left main coronary in the right ventricular cavity before entering the interventricular septum. A phasic systolic compression was demonstrated by intravascular

From the Departments of Internal Medicine and Cardiology, ${ }^{b}$ Thoracic and Cardiovascular Surgery, ${ }^{\mathrm{a}}$ and Pathology, ${ }^{\mathrm{c}}$ University Hospital, Aachen, Germany.

Received for publication May 28, 1999; accepted for publication July 13, 1999.

Address for reprints: Jaime F. Vazquez-Jimenez, MD, Klinik für Thorax-, Herz- und Gefaßchirurgie Universitätsklinikum der RWTH-Aachen, Pauwelstr 30, D-52057 Aachen, Germany (E-mail: jvazquez-jimenez@post.klinikum.rwth-aachen.de).

J Thorac Cardiovasc Surg 1999;118:963-5

Copyright (C) 1999 by Mosby, Inc.

$0022-5223 / 99 \$ 8.00+0 \quad \mathbf{1 2 / 5 4 / 1 0 1 4 1 9}$ ultrasound (IVUS) corresponding with the entry of the vessel into the interventricular septum.

Clinical summary. A 70-year-old patient was admitted with progressive angina and dyspnea on exertion (Canadian Cardiovascular Society class II-III, New York Heart Association functional class II) and with positive results of stress tests, showing posterolateral ischemia.

Diagnostic coronary angiography revealed a subtotal stenosis of the right coronary artery and a coronary anomaly with origin of the small left coronary artery from the right coronary sinus and an anterior course most likely proximal to the pulmonary trunk without stenosis (Fig 1, A). IVUS demonstrated a short area of systolic vessel compression preceded by a segment that was almost completely surrounded by blood with only a small lateral bridge of tissue (Fig 1, B2$B 3$ ). Despite this very uncommon ultrasound finding, the true course of the vessel was not yet understood.

The patient underwent elective percutaneous transluminal coronary angioplasty of the right coronary artery with stent implantation. Four months later the patient had severe in-stent restenosis that was successfully treated with rotablation and a second angioplasty. Two months later the patient returned with angina. At that time the right coronary artery was completely occluded. The patient was then referred for a bypass operation.

The operation was performed with extracorporeal circula- 

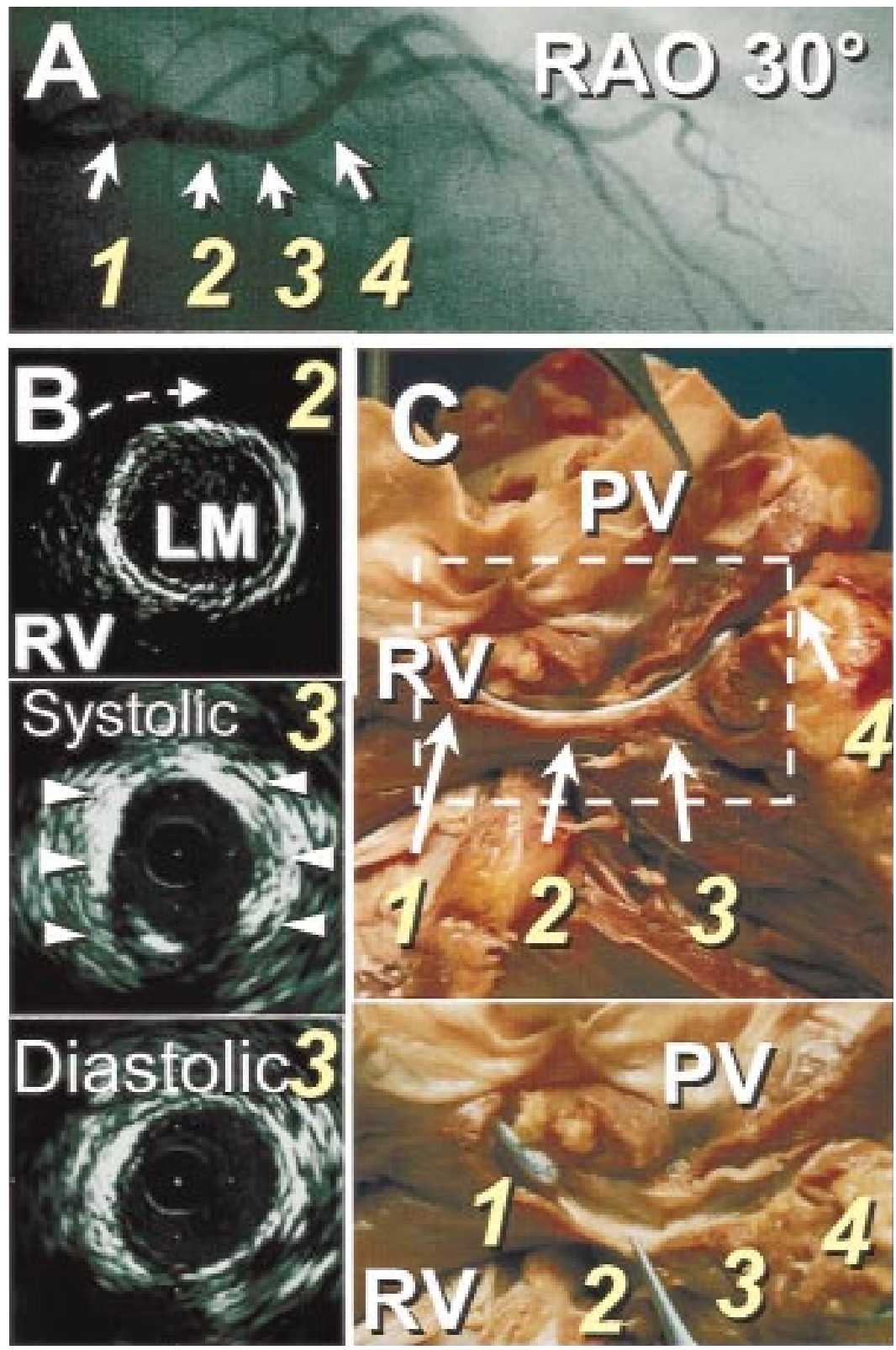

Fig 1. Composite images from coronary angiography (A), intravascular ultrasound (IVUS) (B), and postmortem autopsy of a 70-year-old patient with anomalous origin of the left coronary artery (C). A, Angiographic stopframe image in the $30^{\circ}$ right anterior oblique projection of the left coronary artery with origin from the right coronary sinus with an anterior course and without significant atherosclerosis. $\mathbf{B}$, The numbers 1 to 4 correspond to the IVUS images and the postmortem autopsy. The left coronary artery is almost completely surrounded by blood $(B ; 2)$. Moderate systolic vessel compression at rest $(B ; 3)$, and diastolic appearance at entry site of the interventricular septum $(B ; 3)$. C, A probe inserted through the ostium demonstrates the lumen of the left main coronary artery. 1-2, Anterior wall course of the right ventricle $(1.5 \mathrm{~cm}) ; 2-3$, free portion in the right ventricular cave $(0.6$ $\mathrm{cm}) ; 3-4$, intraseptal portion $(1.4 \mathrm{~cm})$. Detail, Probe in the ostium of the left main coronary artery; a clamp fixes the free portion. $L M$, Left main coronary artery; $P V$, pulmonary valve; $R V$, anterior right ventricle.

tion and moderate hypothermia. During cardioplegic arrest the aortic root was examined, but the exact course of the left main coronary artery after exiting the right coronary sinus could not be determined. Two saphenous vein bypass grafts were connected to the right coronary artery and left circumflex artery, and a left internal thoracic artery was used to bypass the left anterior descending artery. The patient did well after the operation, but on the 7 th postoperative day he 
had a severe mesenteric infarction. During surgical resection of the necrotic intestines an extensive posterior myocardial infarction developed and he died.

Autopsy of the heart showed a fresh thrombus in the right coronary bypass graft and patent left internal and circumflex artery bypass grafts. An abnormal single coronary ostium (8 $\mathrm{mm}$ in diameter) was located above the anterior aortic valve cusp. The right coronary artery arising from this orifice was dominant, supplying most of the posterior wall of the left ventricle. The left coronary artery also arose from the single ostium and turned immediately in a sharp angle between the aorta and the pulmonary trunk through the right ventricular wall into the right ventricular cavity (Fig $1, C$ ). It then coursed below the pulmonary valve with only a small bridge of endocardial tissue connecting the vessel to the wall; thus it was almost completely surrounded by fluid, as seen in IVUS imaging. The subsequent segment, where phasic systolic compression was seen in IVUS, corresponded with the entry of the vessel into the interventricular septum. Beyond the septal course, the vessel reached the epicardium, where it divided into a left anterior descending and a circumflex branch.

Discussion. In a review of about 126,595 patients undergoing coronary arteriography at the Cleveland Clinic Foundation, Yamanaka and $\mathrm{Hobbs}^{3}$ found coronary artery anomalies in 1686 patients ( $1.3 \%$ incidence). Of the 1686 patients, 22 patients $(1.3 \%$; 0.017 incidence) had an ectopic origin of the left main coronary artery from the right coronary sinus. In this anomaly, the entire left coronary artery arises from the right sinus of Valsalva. The right coronary artery may arise separately or share a common ostium with the left coronary artery. Five anatomic subtypes exist and are classified according to the relationship of the anomalous left coronary artery with the aorta and the pulmonary artery: that is, "anterior," "between," "septal," "posterior," and "combined." In this series the "septal" subtype was the most common and is called the "intramyocardial" or "tunneled" anomalous variation. In this subtype the left main coronary artery crosses the superior aspect of the crista supraventricularis, passes a variable distance through the septum, and then becomes epicar- dial at the middle of the septum, where it divides into the left anterior descending and the circumflex arteries. The clinical significance of this anomaly is controversial ${ }^{4,5}$ because most patients are free of symptoms in the absence of coronary disease in other vessels. However, this condition is sometimes the sole cardiac anomaly in patients with sudden and unexpected death. ${ }^{2,5}$ The mechanism of death remains unknown. In this case we document a new variant with a free portion of the left coronary artery coursing through the right ventricular cavity before entering the septum. At the entry of the vessel into the interventricular septum, a phasic systolic compression at rest was documented with IVUS-thus a "functional stenosis." Although the clinical relevance of this systolic narrowing of the vessel is difficult to evaluate, it may be an important cause of ischemia. In the present patient, symptomatic angina revealed stenosis of the dominant right coronary artery. If functional stenosis occurs also in the classic form of this anomaly - an intramyocardial course of the left main coronary at the entry of the vessel into the interventricular septum from the crista supraventricularis-then this could be the mechanism of coronary insufficiency followed by sudden death in those patients. ${ }^{2,5}$

\section{REFERENCES}

1. Becker AE. Congenital coronary arterial anomalies of clinical relevance. Coron Artery Dis 1995;6:187-93.

2. Corrado D, Thiene G, Cocco P, Frescura C. Non atherosclerotic coronary artery disease and sudden death in the young. Br Heart J 1992;68:601-7.

3. Yamanaka O, Hobbs RE. Coronary artery anomalies in 126,595 patients undergoing coronary arteriography. Cathet Cardiovasc Diagn 1990;21:28-40.

4. Roberts WC. Major anomalies of coronary arterial origin seen in adulthood. Am Heart J 1986;111:941-63.

5. Roberts WC, Diccico BS, Waller BF, Kishel JC, McManus BM, Dawson SL, et al. Origin of the left main from the right coronary artery or from the right aortic sinus with intramyocardial tunneling to the left side of the heart via the ventricular septum: the case against clinical significance of myocardial bridge or coronary tunnel. Am Heart J 1982;104:303-5. 